\title{
Touraine-Solente-Gole Syndrome- A Rare Cause of Familial Periostosis
}

\author{
Ajay Sharawat ${ }^{1}$, Girendra Shankar², Kamal Kumar Sen³, Tamanna ${ }^{4}$ \\ ${ }^{1}$ Department of Radiodiagnosis, KIMS, Bhubaneswar, Odisha, India. ${ }^{2}$ Department of \\ Radiodiagnosis, KIMS, Bhubaneswar, Odisha, India. ${ }^{3}$ Department of Radiodiagnosis, KIMS, \\ Bhubaneswar, Odisha, India. ${ }^{4}$ Department of Pathology, KIMS, Bhubaneswar, Odisha, India.
}

\section{INTRODUCTION}

Touraine-Solente-Gole syndrome also known as Rosenfeld-Kloepfer syndrome or primary pachydermoperiostosis is an autosomally inherited disorder. It is an entity of varied presentation, which in its absolute form involves pachyderma (thickening of the facial skin), skeletal changes (periostosis), excessive sweating (hyperhidrosis), with acropachia (digital clubbing). We report a case of complete form of the same with quintessential skeletal and dermatological features. Radiographs of patient with symmetrical coarse periostosis of long bones with classic clinical features were essential in clinching the diagnosis. Consequently, describing the importance of radiological approach in diagnosis of Touraine-Solente-Gole syndrome.

In 1935, the three dermatologists Touraine, Solente, and Gole described a familial variant of hypertrophic osteoarthropathy presenting in three forms, namely complete (periostosis and pachyderma), incomplete (without pachyderma), and the forme fruste (pachydermia with minimal skeletal changes).(1) Pachydermoperiostosis is an insidious disorder characterized by clubbing (acropachy) of the fingers and toes; thickening of the skin (pachyderma), usually of the face; excessive sweating (hyperhidrosis); and new bone formation associated with joint pain.(2) Although the pathogenesis is not clearly defined It is basically considered to be a genetic disorder involving 15-hydroxyprostaglandin dehydrogenase, the main enzyme of prostaglandin degradation thus leading to symptoms related to raised prostaglandin levels, developing gradually from adulthood.(3) A familial history is present in over $50 \%$ of cases and males are said to be more commonly affected, with a male to female ratio of 7:1.

The exact incidence of this rare disease is not known but the estimated prevalence is $0.16 \%{ }^{(4)}$ Borochowitz et al. previously established that the diagnosis should only be made when at least two of the following are present: positive family history, clubbing, hypertrophic skin changes, and bone pain/radiographic changes.(5) Radiological features noted are similar to those seen in hypertrophic osteoarthropathy present early in life, and often start after puberty. Though the periosteal new bone is like that seen in hypertrophic osteoarthropathy, it is often coarser and may extend further along the shafts to the epiphyses. However, No related chest disease is found. The skin of the face, especially the forehead, becomes thickened and greasy with acne and hyperhidrosis.
Corresponding Author: Dr. Girendra Shankar, Postgraduate Resident, Department of Radiodiagnosis, Kalinga Institute of Medical Sciences, Bhubaneswar, Odisha, India.

E-mail: girendra@outlook.in

DOI: $10.14260 / j e m d s / 2020 / 193$

Financial or Other Competing Interests: None.

How to Cite This Article:

Sharawat A, Shankar G, Sen KK, et al. Touraine-solente- gole syndrome- a rare cause of familial periostosis. J. Evolution Med. Dent. Sci. 2020;9(11):897-899, DOI: 10.14260/jemds/2020/193

Submission 14-12-2019,

Peer Review 20-02-2020,

Acceptance 29-02-2020,

Published 16-03-2020.

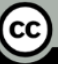




\section{PRESENTATION OF CASE}

A 23-year-old male presented with complaints of pain and swelling around ankle, skin thickening over forehead, morphological abnormality of nails of fingers and toes since 8 years. Pain was insidious in onset, gradually progressing over past 8 years. No restriction of movement but movement was associated with the pain. The skin of the face, especially the forehead, was thickened and greasy with acne and hyperhidrosis. History of presence of similar features in father suggested familial inheritance. Various laboratory investigations like thyroid profile, parathyroid hormone, serum calcium, serum phosphorus, serum albumin, alkaline phosphatase, and IGF-1, ESR and CRP level were done. All laboratory investigations were within normal limits except for elevated alkaline phosphatase and CRP levels. A sample of skin biopsy was taken and sent for histopathological examination which showed hyperplastic reaction in dermis and epidermis layers with features suggestive of pachydermia.

Radiographs of both lower and upper extremities were done at first followed by a chest radiograph. Ends of long bones appeared widened and showed diffuse symmetrical periosteal reaction suggesting new bone formation. Primary diagnosis given to the patient was of Hypertrophic Osteoarthropathy. Sonogram of abdomen was done to ascertain the presence of any accompanying pathology. Chest radiograph and USG abdomen were found to be normal, which ruled out most of the secondary causes leading to a diagnosis of Primary Hypertrophic Osteoarthropathy. The association of clubbing and pachydermia with periostitis in familial inheritance fulfilled the diagnostic criteria given by Borochowitz(5) and the patient was diagnosed with primary pachydermoperiostosis (PDP).

\section{DISCUSSION}

We report a case of 23 year old male patient with complaints of pain and swelling around ankles, thickening of skin over forehead and morphological abnormalities of nails since 8 years. All examination findings, radiographic and laboratory investigations pointed towards the diagnosis of Pachydermoperiostosis (PDP). Hypertrophic osteoarthropathy can be divided into 2 forms- Primary and Secondary. Primary form (PDP) accounts only $5 \%$ of all cases of HOA. Secondary form occurs in consequence to underlying cardiopulmonary disease and malignancies.

The diagnostic criteria for PDP include two components

- Major Criteria: pachyderma, periostosis, finger clubbing.

- Minor Criteria: hyperhidrosis, arthralgia, gastric ulcer, cutis verticis gyrate, blepharoptosis, joint effusion, column-like legs, oedema, seborrhoea, acne, flushing.(6),(7)

Our patient had all three major criteria i.e., hyperostosis, finger clubbing, and pachyderma and out of minor criteria hyperhidrosis, arthralgia, acne and flushing were present confirming a final clinical diagnosis of Primary Pachydermoperiostosis. Pathogenesis of PDP is poorly understood. However, recently identified mutations in HPGD gene on chromosome 4q33-34 which codes for 15hydroxyprostaglandin dehydrogenase and SLCO2A1 gene which encodes a prostaglandin transporter protein are responsible for the familial form of PDP. Thus, Homozygous individuals tend to develop elevated prostaglandin E2 levels leading to PDP.(3),(8) A diffuse symmetric periosteal reaction is seen on radiographic examination in a patient with hypertrophic osteoarthropathy, Predominantly involving the long bones such as tibia and phalanges.(9) Characteristic involvement of diaphysis followed by metaphysis and finally epiphysis is a signal for disease advancement. A typical feature of primary hypertrophic osteoarthropathy is inclusion of epiphysis in the disease process, which is not usual in the secondary form of the disease.

This disease is characteristically associated with noninvolvement of the marrow and the adjacent soft tissues. Presence of symptoms incriminating involvement of these tissues would likely suggest some other disease.(9) Radiographic study of distal limbs may show acral osteolysis and hypertrophy of the of the digital tufts. When involving joints, perifocal soft tissue swelling is observed without any associated arthritic changes such as joint space narrowing and articular erosions ${ }^{(9)}$ Skin changes are most commonly noted in idiopathic form of the disease as thickened skin folds. This is mostly noticeable on the face and is known as leonine face and bilateral or unilateral eye ptosis (blepharoptosis). Other manifestations are acne, seborrhea, oily skin and palmoplantar hyperhidrosis. In contrast to PDP, acromegaly a close differential, presents with skeletal abnormalities of facial and calvarial bones, along with raised (IGF-1) insulin-like growth factor-1 levels and positive oral glucose tolerance test.

There are few other diseases that can be close differentials in the diagnosis for primary pachydermoperiostosis and can cause impediment in diagnosis, such as certain types of psoriatic arthritis such as psoriatic onychopachydermoperiostosis. It differs in its presentation due to restriction to the extremities, nail involvement and association with psoriasis. However, in absence of psoriasis such presentation can be seen with rheumatoid arthritis. In our patient these were ruled out due to absence of history suggestive of autoimmune arthritis and normal erythrocyte sedimentation rate. Other closely associated diagnosis would be thyroid acropachy, a complication of hypothyroidism. Which was ruled out due to absence of thyroid ophthalmopathy, pretibial edema in physical examination and normal thyroid function tests.

In a patient with symptoms of periostitis, there are few other disorders to be considered such as, hypervitaminosis A, fluorosis and Caffey's disease. In our patient there were no clinical features or radiological evidence indicative of these diagnoses. Similar radiographic and dermatological findings were seen in case series reported by Matucci-Cernic et al. Rastogi et al., in addition to the symptoms demonstrated by our case, suggested association of spondylotic changes. Alaya et al. in a recent case series proposed similar findings to be leading to a diagnosis of pachydermoperiostosis. In addition to other dermatological findings, case described by Sharma et al showed cutis verticis gyrata (furrowing oof skin over face and scalp). Our radiographic Features were also similar to Joshi et al, Abdullah et al, and Gourine et al.

Since pathogenesis of PDP primarily revolves around PGE2 formation, symptomatic management with non-steroidal antiinflammatory drugs, corticosteroids, or colchicine is administered for pain management. Recent advancements in 
PDP therapy like oral etoricoxib or bisphosphonates for arthritis coupled with arthroscopic synovectomy have emerged as superlative treatment strategies.

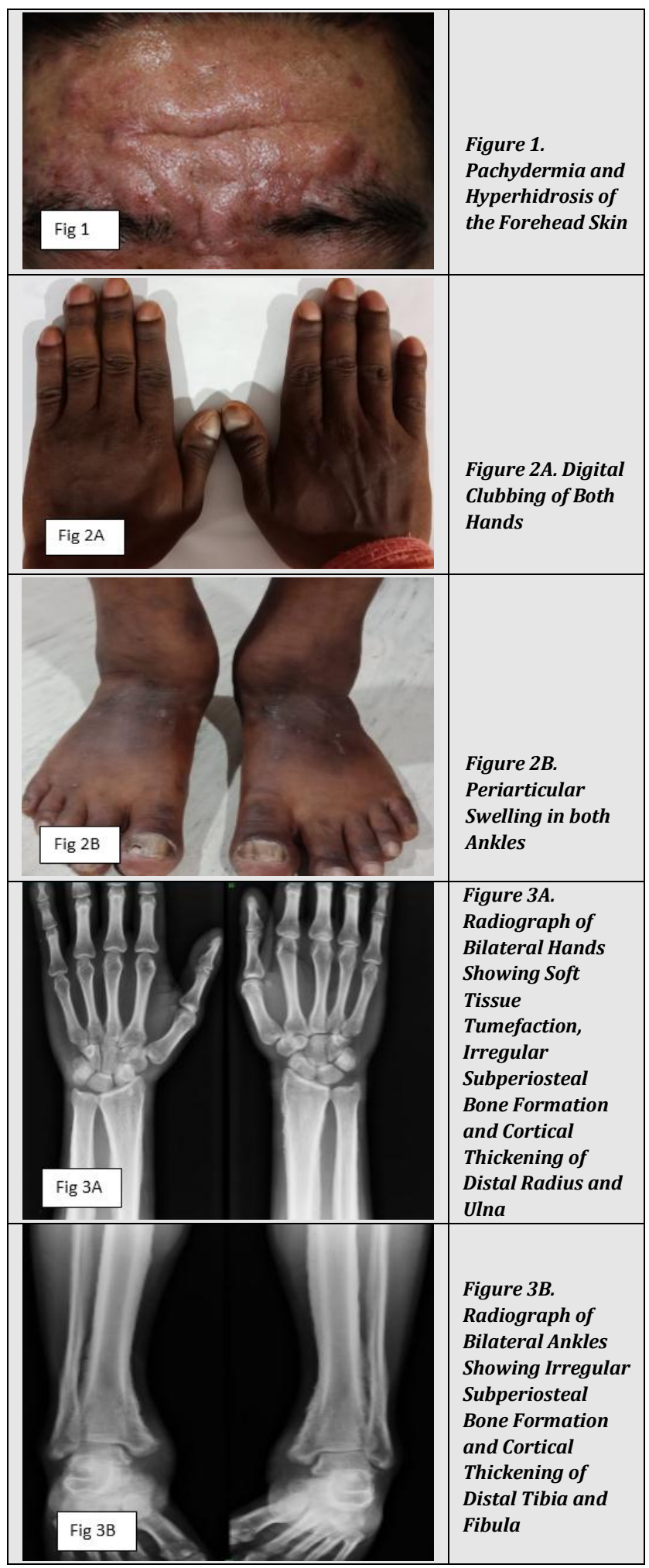

\section{CONCLUSIONS}

Touraine-Solente-Gole Syndrome clinically presents as periostosis which needs to be differentiated from secondary hypertrophic osteoarthropathy, autoimmune arthropathies, thyroid acropachy and acromegaly. Primary periostosis, when accompanied with pachyderma and hyperhidrosis implies a diagnosis of Touraine-Solente-Gole syndrome which can be proficiently managed on accurate diagnosis.

\section{REFERENCES}

[1] Touraine A, Solente G, Gole L. Un syndrome osteodermopathique: la pachydermie plicaturee avec pachyperiostose des extremites. Presse Med 1935;43:1820-4.

[2] Kumar S, Sidhu S, Mahajan BB. Touraine-soulente-Gole syndrome: a rare case report and review of the literature. Ann Dermatol 2013;25(3):352-5.

[3] Uppal S, Diggle CP, Carr IM, et al. Mutations in 15hydroxyprostaglandin dehydrogenase cause primary hypertrophic osteoarthropathy. Nature Genetics 2008;40(6):789-93.

[4] Jajic Z, Jajic I, Nemcic T. Primary hypertrophic osteoarthropathy: clinical, radiologic and scintigraphic characteristics. Archives of Medical Research 2001;32(2):136-42.

[5] Buyse ML. Birth defects encyclopedia: the comprehensive, systematic, illustrated reference source for the diagnosis, delineation, etiology, biodynamics, occurrence, prevention and treatment of human anomalies of clinical relevance. Dover, MA: Blackwell Science Publications 1990: p. 1349-50.

[6] Martinez-Lavin M, Matucci-Cerinic M, Jajic I, et al. Hypertrophic osteoarthropathy: consensus on its definition, classification, assessment and diagnostic criteria. Journal of Rheumatology 1993;20(8):1386-7.

[7] Jojima H, Kinoshita K, Naito M. A case of pachydermoperiostosis treated by oral administration of a bisphosphonate and arthroscopic synovectomy. Modern Rheumatology 2007;17(4):330-2.

[8] Matucci-Cerinic M, Lotti T, Jajic I, et al. The clinical spectrum of pachydermoperiostosis (primary hypertrophic osteoarthropathy). Medicine (Baltimore) 1991;70(3):208-14.

[9] Rastogi R, Suma GN, Prakash R, et al. Pachydermoperiostosis or primary hypertrophic osteoarthropathy: a rare clinicoradiologic case. Indian Journal of Radiology and Imaging 2009;19(2):123-6. 